www.jmscr.igmpublication.org

Impact Factor 5.84

Index Copernicus Value: 83.27

ISSN (e)-2347-176x ISSN (p) 2455-0450

crossref DOI: _https://dx.doi.org/10.18535/jmscr/v5i8.170

Journal Of Medical Science And Clinical Research

\title{
Volume of contrast to creatinine clearance ratio: a novel pharmacokinetic index for prediction of contrast induced nephropathy in stage three chronic kidney disease patients undergoing coronary angioplasty
}

Authors

\section{Dr Sanjai Pattu Valappil MD.DM.DNB, Dr Praveen Velappan MD.DM, Dr Sunitha Viswanathan MD.DM.FESC.FSCAI, Dr Alummoottil George Koshy MD.DM.FESC.FSCAI.FACC.FRCP, Dr Prabha Nini Gupta MD.DM.FSCAI, Dr Radhakrishnan Vallikkattu Velayudhan MD.DM.FESC. FACC, Dr Mathew Iype} MD.DNB.DM.DNB, Dr Dilip Mazhavancheri Narayanan MD.DM

Department of Cardiology, Government Medical College, Thiruvananthapuram

\begin{abstract}
Objective: The aim of the study was to identify the optimal 'Volume of contrast to Creatinine Clearance ratio' $\{\mathrm{V} / \mathrm{CrCl}\}$ for prediction of contrast induced nephropathy $\{\mathrm{CIN}\}$ in stage III chronic kidney disease $\{C K D\}$ patients undergoing coronary angioplasty.

Methods: This was a prospective observational study where stage III CKD patients, with an estimated glomerular filtration rate (eGFR) between $30-60 \mathrm{ml} / \mathrm{mt}$ undergoing elective percutaneous coronary intervention $\{P C I\}$ over a period of 15 months were evaluated prospectively for the development of CIN. Receiver-operator characteristic $\{R O C\}$ curves were used to identify the optimal sensitivity and specificity for the observed range of $\mathrm{V} / \mathrm{CrCl}$. The predictive value of $\mathrm{V} / \mathrm{CrCl}$ for the risk of CIN was assessed using multivariable logistic regression.
\end{abstract}

Results: 100 stage III CKD patients underwent PCI during the study period. The incidence of CIN was 29 $\%$. Based on the 'Volume of contrast /Creatinine clearance ratio $\{\mathrm{V} / \mathrm{CrCl}\}$ the quartiles of the $\mathrm{V} / \mathrm{CrCl}$ ratio for all the patients were as follows: quartile (Q1) (<3.45, $n=25) ; Q 2$ (3.45-4.28, $n=25)$; Q3 (4.28-5.31, $n=25)$; and $Q 4(>5.31, n=25)$. The receiver-operator characteristic curve analysis indicated that a $\mathrm{V} / \mathrm{CrCl}$ ratio of 4 was a fair discriminator for the development of CIN \{C-statistic 0.69\}. After adjusting for other known predictors of CIN, a $\mathrm{V} / \mathrm{CrCl}$ ratio of 4 was found to be significantly associated with the development of CIN \{OR: 2.849, $95 \%$ CI: 0.972-8.363, $p=0.05$ \}

Conclusion: $\mathrm{A} \mathrm{V} / \mathrm{CrCl}$ ratio of $>4$ was a significant and independent predictor of CIN in stage III CKD patients undergoing PCI.

Keywords: Contrast; nephropathy; angioplasty.

\section{Introduction}

Iodinated radiocontrast is an intergral tool of interventional cardiology. It was the serendipitous observation of Osborne that the urine of syphilitic patients who were treated with iodine based compounds turned radioopaque which blossomed into the birth of iodine based contrast media. Osborne then performed the first successful clinical pyelogram at the Mayo clinic in $1923^{(1)}$. Subsequently it was Brooks in 1924 who pioneered the use of sodium iodide to perform the first ever angiogram of the femoral artery ${ }^{(2)}$. 
Multitudes of experiments with the modifications in the structure of iodine containing contrast agents to reduce their toxicity and improve efficacy have been underway since then. In 1968 Almén proposed new, low-toxicity, nonionic, mono-meric and dimeric contrast media, and since then the toxicity of different contrast media has mainly been attributed to their osmolality, viscosity, and chemotoxicity ${ }^{(3)(4)(5)}$. The principal deterrent to the use of intravascular iodinated contrast media is the development of contrast induced nephropathy $\{\mathrm{CIN}\}$. CIN is defined as the contrast mediated damage to the renal function as manifested by the increase in serum creatinine by $0.5 \mathrm{mg} / \mathrm{dl}$ or a $25 \%$ increase from the baseline ${ }^{(6)}$. A number of preventive measures have been in practice to tackle this serious complication such as pre- procedural hydration with isotonic saline, the use of iso-osmolar non-ionic contrast media , loading with $\mathrm{N}$ - acetyl cysteine, and the withdrawal of nephrotoxic drugs ${ }^{(7)(8)(9)(10)(11)}$. However the sine qua non in the prevention of CIN is and will always be the judicious use of contrast media. Multiple studies have been undertaken to identify the upper limit of contrast media that would predict the risk of CIN. The ratio of the volume of contrast media to the creatinine clearance is an effective pharmacokinetic index that has been studied in various populations for the prediction of CIN. ${ }^{(12)(13)(14)(15)}$ Across numerous studies there is a wide variation in this index from as high as 6.15 to as low as 2.62. The current study was undertaken to identify the optimal 'Volume of contrast to Creatinine Clearance ratio' $\{\mathrm{V} / \mathrm{CrCl}\}$ for prediction of contrast induced nephropathy $\{\mathrm{CIN}\}$ in stage III chronic kidney disease $\{C K D\}$ patients undergoing coronary angioplasty.

\section{Materials and Methods}

\section{Study design}

This was a prospective observational study conducted at the Department of Cardiology, Government Medical College Trivandrum for a period of 15 months from January 2015.

Study protocol

\section{Inclusion criteria}

1. Adults aged $>18$ years with CKD stage III as defined as eGFR of: $30-60 \mathrm{~mL} / \mathrm{min}$ $/ 1.73 \mathrm{~m} 2$ calculated by the CockcroftGault formula.

2. Patients admitted for elective PCI.

\section{Exclusion criteria}

1. Patients undergoing routine hemodialysis or peritoneal dialysis.

2. Patients admitted with ST elevation myocardial infarction $\{$ STEMI .

3. Patients with cardiogenic shock.

Prophylactic measures for prevention of CIN were instituted in all the patients namely, continuous intravenous saline infusion $(0.9 \%) 12$ hours before to 24 hours after PCI $(1 \mathrm{~mL}$ per kilogram of body weight per hour), oral $\mathrm{N}$ acetylcysteine $600 \mathrm{mg}$ twice orally on the day before and on the day of PCI and withdrawal of nephrotoxic drugs. In all patients Iodixanol, a non ionic isoosmolar contrast was used .

\section{Definitions}

CKD stage III: eGFR of: $30-60 \mathrm{~mL} / \mathrm{min} / 1.73$ $\mathrm{m} 2$ calculated by the Cockcroft- Gault formula.

CIN: CIN was defined as an increase in serum creatinine concentration of $0.5 \mathrm{mg} / \mathrm{dL}(44 \mathrm{~mol} / \mathrm{L})$ or $25 \%$ above baseline within 48 hours after contrast administration. ${ }^{(6)}$

\section{Statistical Analysis}

Continuous variables were expressed as minimum, maximum, mean, standard deviation (SD), and qualitative data were presented as percentages and frequencies. Continuous variables were analysed by a Student's t test and categorical variables by the Chi square test when appropriate. Receiveroperator characteristic $\{$ ROC $\}$ curves were used to identify the optimal sensitivity and specificity for the observed range of $\mathrm{V} / \mathrm{CrCl}$. The risk predictors for CIN were initially screened for univariate associations at $\mathrm{p}=0.20$ and the identified variables were then assessed in a forward stepwise manner using a $\mathrm{p}$ value criterion of $<0.05$. The results of this model were presented as an Odds Ratio (OR) and a 95\% confidence intervals $(95 \% \mathrm{CI})$ for OR. A 2-sided probability value of 0.05 was considered to indicate statistical 
significance throughout the analysis .The statistical analyses were performed with SPSS software \{version 17.0\}. Based on the 'Volume of contrast $/$ Creatinine clearance ratio $\{\mathrm{V} / \mathrm{CrCl}\}$ the study patients were stratified and analysed into quartiles.

\section{Results}

During the study period of 15 months, 100 high risk patients with CKD stage III underwent elective PCI and were prospectively evaluated for the development of CIN. Based on the 'Volume of contrast $/$ Creatinine clearance ratio $\{\mathrm{V} / \mathrm{CrCl}\}$ the quartiles of the $\mathrm{V} / \mathrm{CrCl}$ ratio for all the patients were as follows: quartile (Q1) $(<3.45, \mathrm{n}=25)$; Q2 (3.45-4.28, $\mathrm{n}=25)$; Q3 (4.28-5.31, $\mathrm{n}=25)$; and Q4 $(>5.31, \mathrm{n}=25)$.

\section{Baseline demographics}

The baseline demographic characteristics of the patients among the various $\mathrm{V} / \mathrm{CrCl}$ ratio quartiles are shown in table 1 and 2

Table1: Baseline demographic characteristics of the patients among the $\mathrm{V} / \mathrm{CrCl}$ ratio quartiles.

\begin{tabular}{|c|c|c|c|c|c|c|c|c|c|}
\hline & \multicolumn{8}{|c|}{ Dye Volume /eGFR } & \multirow{3}{*}{$P$} \\
\hline & \multicolumn{2}{|c|}{$\begin{array}{c}\mathrm{Q} 1 \\
(<3.45, \\
\mathrm{N}=25)\end{array}$} & \multicolumn{2}{|c|}{$\begin{array}{c}\mathrm{Q} 2 \\
(3.45-4.28 \\
\mathrm{N}=25)\end{array}$} & \multicolumn{2}{|c|}{$\begin{array}{c}\mathrm{Q} 3 \\
(4.28-5.31 \\
\mathrm{N}=25) \\
\end{array}$} & \multicolumn{2}{|c|}{$\mathrm{Q} 4(>5.31, \mathrm{~N}=25)$} & \\
\hline & $\mathrm{N}$ & $\%$ & $\mathrm{~N}$ & $\%$ & $\mathrm{~N}$ & $\%$ & $\mathrm{~N}$ & $\%$ & \\
\hline \multicolumn{10}{|c|}{ Demographics } \\
\hline Age $>75$ & 1 & 4 & 2 & 8 & 5 & 20 & 8 & 32 & 0.048 \\
\hline Male & 20 & 80 & 19 & 76 & 21 & 84 & 23 & 92 & 0.479 \\
\hline HT & 14 & 56 & 16 & 64 & 19 & 76 & 15 & 60 & 0.488 \\
\hline DLP & 7 & 28 & 6 & 24 & 7 & 28 & 7 & 28 & 0.985 \\
\hline Smoker & 14 & 56 & 9 & 36 & 8 & 32 & 13 & 52 & 0.239 \\
\hline Anemia & 8 & 32 & 14 & 56 & 13 & 52 & 15 & 60 & 0.200 \\
\hline DM & 14 & 56 & 16 & 64 & 14 & 56 & 13 & 52 & 0.855 \\
\hline $\mathrm{EF}<50 \%$ & 15 & 60 & 17 & 68 & 18 & 72 & 17 & 68 & 0.835 \\
\hline \multicolumn{10}{|c|}{ Mehran Risk score } \\
\hline MRS $<10$ & 16 & 64 & 15 & 60 & 16 & 64 & 11 & 44 & 0.048 \\
\hline $11-15$ & 9 & 36 & 10 & 40 & 8 & 32 & 9 & 36 & 0.656 \\
\hline$>15$ & 0 & 0 & 0 & 0 & 1 & 4 & 5 & 20 & 0.032 \\
\hline
\end{tabular}

Table 2: Baseline demographic characteristics of the patients among the $\mathrm{V} / \mathrm{CrCl}$ ratio quartiles

\begin{tabular}{|c|c|c|c|c|c|c|c|c|c|}
\hline & \multicolumn{8}{|c|}{ Dye Volume /eGFR } & \multirow{3}{*}{$\mathrm{p}$} \\
\hline & \multicolumn{2}{|c|}{$\begin{array}{l}\text { Q1 } \\
(<3.45, \\
\mathrm{N}=25) \\
\end{array}$} & \multicolumn{2}{|c|}{$\begin{array}{l}\text { Q2 } \\
(3.45-4.28, \\
\mathrm{N}=25) \\
\end{array}$} & \multicolumn{2}{|c|}{$\begin{array}{l}\text { Q3 } \\
(4.28-5.31, \\
\mathrm{N}=25) \\
\end{array}$} & \multicolumn{2}{|c|}{$\mathrm{Q} 4(>5.31, \mathrm{~N}=25)$} & \\
\hline & mean & $\mathrm{sd}$ & mean & sd & mean & sd & mean & sd & \\
\hline \multicolumn{10}{|l|}{ Demographics } \\
\hline Age & 58.7 & 8.9 & 62.0 & 8.0 & 65.9 & 8.8 & 68.5 & 8.7 & .023 \\
\hline BMI $\{$ body mass index $\}$ & 26.0 & 3.3 & 24.8 & 2.1 & 22.0 & 3.1 & 20.1 & 2.5 & .040 \\
\hline Mehran Risk score & 9.2 & 2.7 & 9.7 & 3.1 & 10.1 & 3.0 & 11.5 & 3.7 & .049 \\
\hline \multicolumn{10}{|l|}{ Lab parameters } \\
\hline Men LVEF & 55.0 & 10.7 & 53.2 & 11.0 & 56.9 & 11.8 & 52.9 & 13.0 & .603 \\
\hline $\mathrm{Hb}$ baseline & 12.1 & 1.4 & 12.0 & 1.9 & 12.0 & 1.0 & 11.9 & 1.4 & .971 \\
\hline S.Cr Baseline & 1.48 & 0.20 & 1.48 & 0.23 & 1.5 & 0.17 & 1.60 & 0.22 & .139 \\
\hline eGFR & 51.2 & 8.8 & 47.2 & 5.6 & 46.6 & 8.9 & 41.4 & 6.4 & .001 \\
\hline MDRD & 51.6 & 7.2 & 51.6 & 6.8 & 50.4 & 6.0 & 46.2 & 7.9 & .021 \\
\hline
\end{tabular}


There was a definite trend among all the quartile of patients with the patients in the higher quartiles being older $\mathrm{p}=0.023\}$, with a lower BMI $\{$ body mass index $\} \quad\{p=0.040\}$, with a lower eGFR $\{\mathrm{p}=0.001\}$ and higher Mehran risk scores $\{\mathrm{MRS}\}\{\mathrm{p}=0.049\}$.

\section{Procedural characteristics}

The procedural characteristics of the patients are shown in table 3 and table 4.

Table 3: The procedural characteristics of the patients among the $\mathrm{V} / \mathrm{CrCl}$ ratio quartiles

\begin{tabular}{|c|c|c|c|c|c|c|c|c|c|}
\hline & \multicolumn{8}{|c|}{ Dye Volume /eGFR } & \multirow{3}{*}{$\mathrm{P}$} \\
\hline & \multicolumn{2}{|c|}{$\begin{array}{c}\mathrm{Q} 1 \\
(<3.45, \\
\mathrm{N}=25)\end{array}$} & \multicolumn{2}{|c|}{$\begin{array}{c}\mathrm{Q} 2 \\
(3.45-4.28, \\
\mathrm{N}=25)\end{array}$} & \multicolumn{2}{|c|}{$\begin{array}{c}\mathrm{Q} 3 \\
(4.28-5.31 \\
\mathrm{N}=25)\end{array}$} & \multicolumn{2}{|c|}{$\mathrm{Q} 4(>5.31, \mathrm{~N}=25)$} & \\
\hline & $\mathrm{N}$ & $\%$ & $\mathrm{~N}$ & $\%$ & $\mathrm{~N}$ & $\%$ & $\mathrm{~N}$ & $\%$ & \\
\hline \multicolumn{10}{|c|}{ Procedural Characteristics } \\
\hline Mutivessel PCI & 12 & 48 & 13 & 52 & 16 & 64 & 17 & 68 & 0.050 \\
\hline CTO PCI & 10 & 40 & 11 & 44 & 15 & 60 & 18 & 72 & 0.037 \\
\hline \multicolumn{10}{|l|}{ Events } \\
\hline HD & 0 & 0 & 0 & 0 & 1 & 4 & 1 & 4 & 0.564 \\
\hline Death & 1 & 4 & 0 & 0 & 0 & 0 & 2 & 8 & 0.286 \\
\hline $\mathrm{CIN}$ & 2 & 8 & 4 & 16 & 9 & 36 & 14 & 64 & 0.034 \\
\hline
\end{tabular}

Table 4: The procedural characteristics of the patients among the $\mathrm{V} / \mathrm{CrCl}$ ratio quartiles

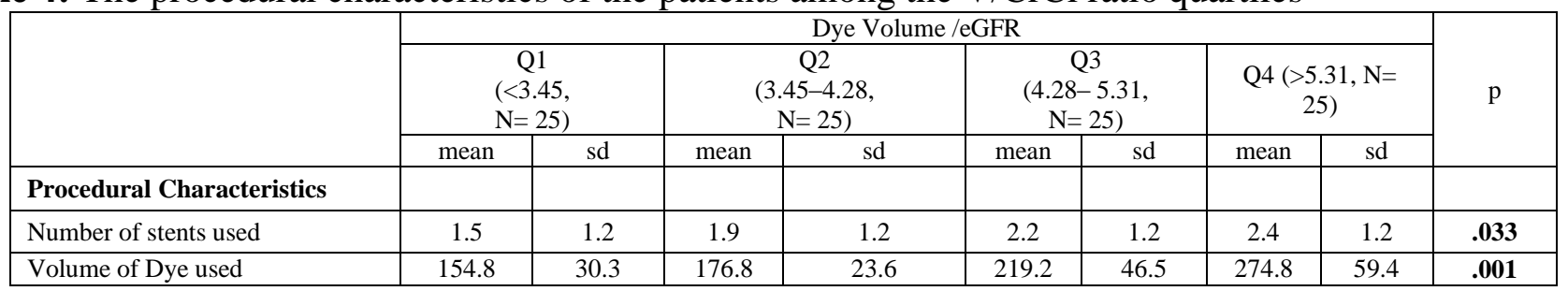

It was seen that the patients in the highest quartiles had more of multivessel PCI $\{\mathrm{p}=0.050\}$ and CTO \{Chronic total occlusion\} PCI $\{\mathrm{p}=0.037\}$. Importantly higher numbers of stents were used with increasing $\mathrm{V} / \mathrm{CrCl}$ quartiles $\{\mathrm{p}=0.33\}$.

\section{Events}

There were a total of 29 patients who developed CIN. It was seen that with increasing quartiles of $\mathrm{V} / \mathrm{CrCl}$ there was a significantly higher incidence of CIN among the patients $\{p=0.035\}$. The patients with CIN were followed up at 2 weeks and 6 weeks for requirement of hemodialysis and cardiac death. Among the 29 patients who developed CIN two patients required hemodialysis one each in the third and the fourth quartile. There were 3 deaths in total, two of which were in the highest quartile $\{\mathrm{V} / \mathrm{CrCl}>5.31\}$ and one in the lowest quartile. This is shown in table 5 and Figure 1

Table 5: Table showing incidence of requirement of hemodialysis, death and $\mathrm{CIN}$ among the $\mathrm{V} / \mathrm{CrCl}$ quartiles.

\begin{tabular}{|c|c|c|c|c|c|c|c|c|c|}
\hline & \multicolumn{8}{|c|}{ Dye Volume /eGFR } & \multirow{3}{*}{$\mathrm{P}$} \\
\hline & \multicolumn{2}{|c|}{$\begin{array}{c}\mathrm{Q} 1 \\
(<3.45, \\
\mathrm{N}=25)\end{array}$} & \multicolumn{2}{|c|}{$\begin{array}{c}\mathrm{Q} 2 \\
(3.45-4.28 \\
\mathrm{N}=25)\end{array}$} & \multicolumn{2}{|c|}{$\begin{array}{c}\mathrm{Q} 3 \\
(4.28-5.31 \\
\mathrm{N}=25) \\
\end{array}$} & \multicolumn{2}{|c|}{$\mathrm{Q} 4(>5.31, \mathrm{~N}=25)$} & \\
\hline & $\mathrm{N}$ & $\%$ & $\mathrm{~N}$ & $\%$ & $\mathrm{~N}$ & $\%$ & $\mathrm{~N}$ & $\%$ & \\
\hline \multicolumn{10}{|c|}{ Events } \\
\hline HD & 0 & 0 & 0 & 0 & 1 & 4 & 1 & 4 & 0.564 \\
\hline Death & 1 & 4 & 0 & 0 & 0 & 0 & 2 & 8 & 0.286 \\
\hline CIN & 2 & 8 & 4 & 16 & 9 & 36 & 14 & 64 & 0.034 \\
\hline
\end{tabular}




\section{JMSCR Vol||05||Issue||08||Page 27017-27024||August}

Figure 1: Figure showing the incidence of $\mathrm{CIN}$ among the $\mathrm{V} / \mathrm{CrCl}$ quartiles.

\section{INCIDENCE OF CIN}

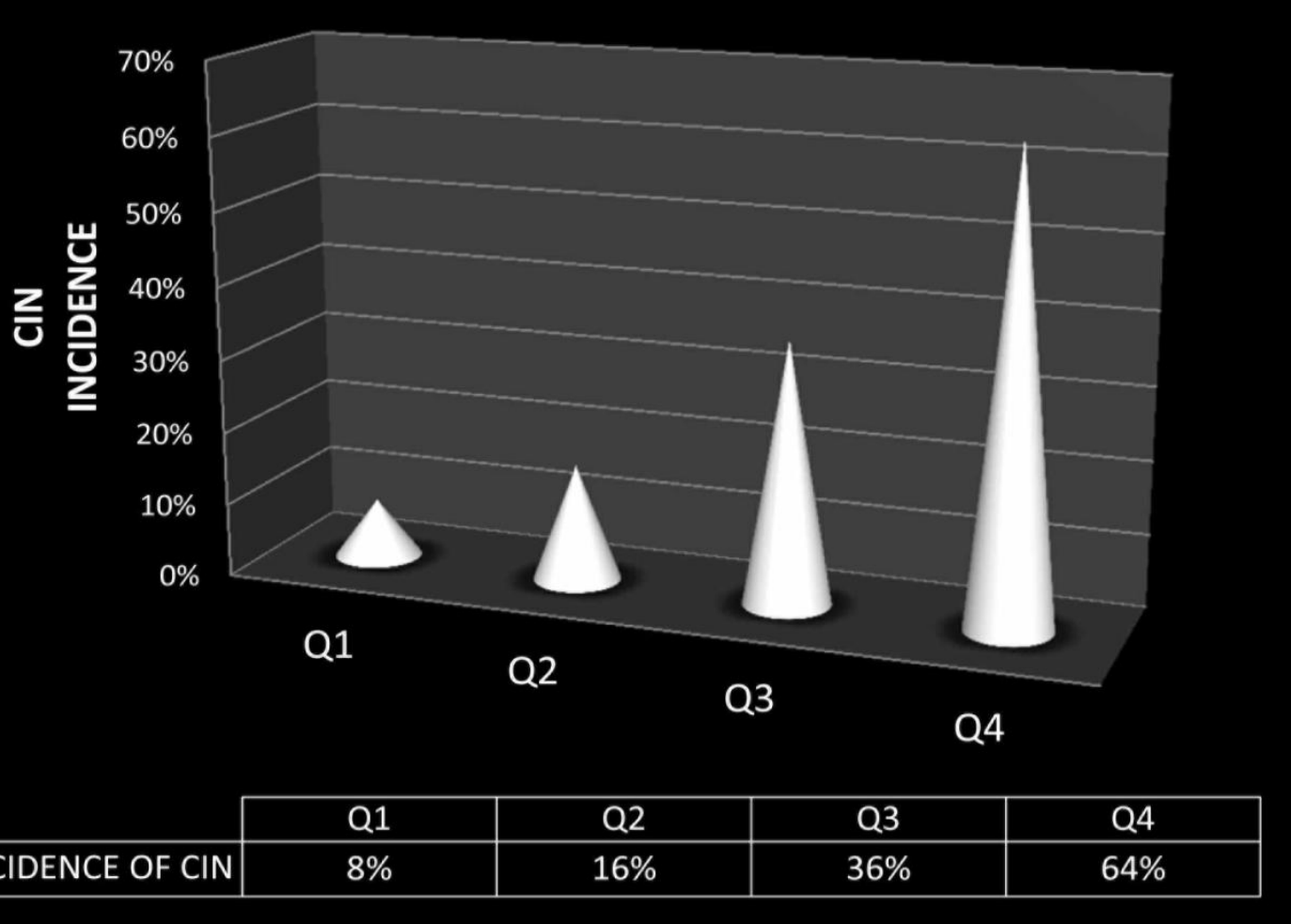

\section{Predictive accuracy of $\mathrm{V} / \mathrm{CrCl}$ for $\mathrm{CIN}$}

The ROC curve analysis showed that the optimal cut-off level for the $\mathrm{V} / \mathrm{CrCl}$ ratio was 4 , which exhibited a $72.4 \%$ sensitivity, $50.7 \%$ specificity,
$37.5 \%$ positive predictive value and $81.8 \%$ negative predictive value for predicting $\mathrm{CIN}\{\mathrm{C}$ statistic :0.64\}.

Figure 2: ROC curve for finding the optimum cut off value of Dye volume EGFR ratio for predicting CIN

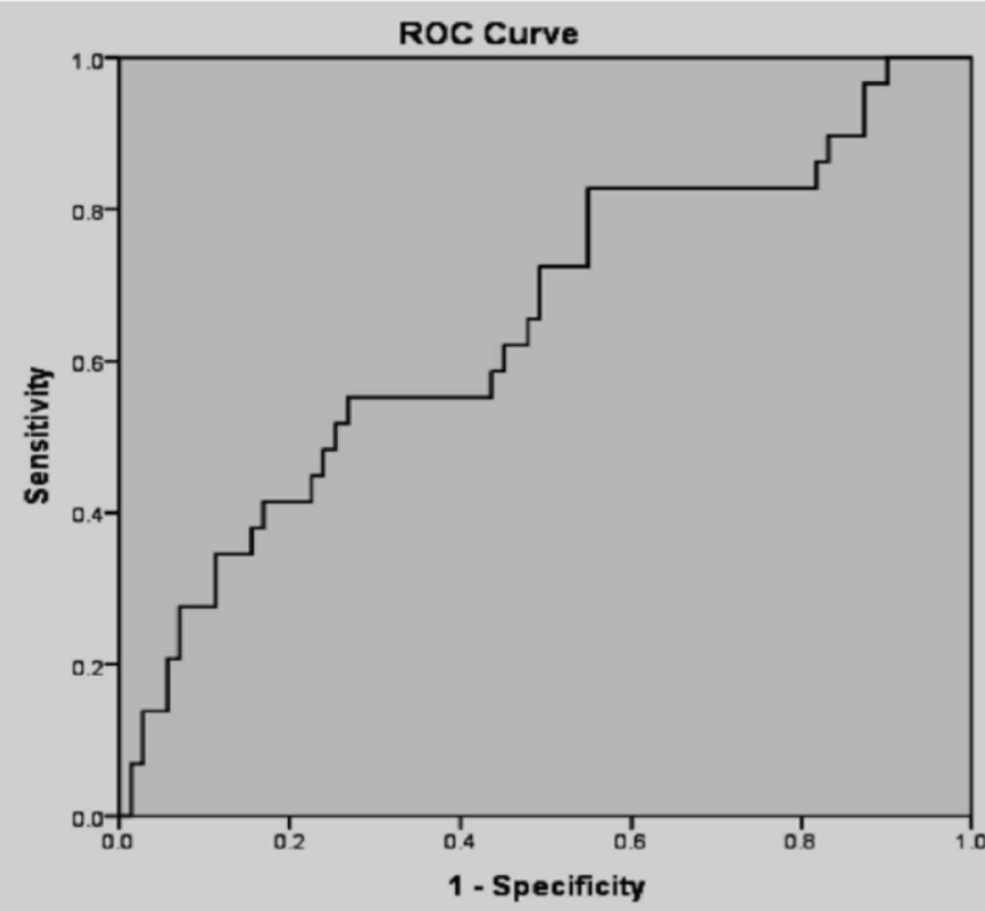


The conventional risk factors for CIN including anaemia, ratio of Volume of contrast to the creatinine clearance $\{\mathrm{V} / \mathrm{CrCl}\}>4$, age more than 75 years, ejection fraction less than $50 \%$, usage of loop diuretics, periprocedural hypotension, the presence of type 2 diabetes mellitus, and systemic hypertension were analysed among the two groups of patients namely those who either developed CIN or did not develop CIN. Univariate analysis was performed for the above variables. The variables with a $\mathrm{p}$ value of less than 0.2 in the univariate analysis were then considered for multivariate analysis .On multivariate analysis it was seen that $\mathrm{V} / \mathrm{CrCl}$ ratio of $>4$ \{OR: $2.849,95$ $\%$ CI: 0.972-8.363, $\mathrm{p}=0.05\}$, anemia \{OR: 3.136, $95 \%$ CI: $0.822-7.773 \mathrm{p}=0.04\}$ and usage of loop diuretics \{OR: 2.112, $95 \%$ CI: $0.776-$ $6.563 \mathrm{p}=0.05\}$ were found to be statistically significant.

\section{Discussion}

CIN has been a bane of interventional cardiology. The unforeseen rise in the serum creatinine after a successful intervention is nightmare for the treating physician. Numerous risk factors have traditionally been associated with an incremental risk of CIN; the foremost among these are the baseline renal dysfunction and the volume of contrast used. Several studies have sought to establish a relationship between the total volume of contrast media administered, baseline renal function, and risk of CIN after PCI. Cigarroa et al in 1989 established the upper limit of contrast exposure for prediction of CIN as five times the body weight divided by the serum creatinine ${ }^{(16)}$. Though this formula has been validated in other studies, it falls short as it does not include the patient's age, which by itself is a portentous risk factor for $\mathrm{CIN}{ }^{(17)}$. The volume of contrast divided by the creatinine clearance $\{\mathrm{V} / \mathrm{CrCl}\}$ ratio is an exceptional pharmacokintetic index as it takes into account the four major risk factors for CIN namely: volume of contrast, serum creatinine, body weight, age and sex of the patient. The first study which established the $\mathrm{V} / \mathrm{CrCl}$ as an index for CIN was by Altmann in 1997 who studied 152 patients with chronic kidney disease (defined as a baseline creatinine $>2.0 \mathrm{mg} / \mathrm{dl}$ ) who underwent angiography, it was seen that a ratio of $>6$ predicted $\mathrm{CIN}^{(18)}$. Subsequently Laskey studied 3,179 consecutive unselected patients undergoing PCI and found that a $\mathrm{V} / \mathrm{CrCl}$ ratio of $>3.7$ predicted the patient at risk for an abnormal early postprocedural increase in creatinine an increase of $>0.5 \mathrm{mg} / \mathrm{dl}$ within 24 hours $\}^{(13)}$. The largest study to date which studied the $\mathrm{V} / \mathrm{CrCl}$ ratio was by Gurm et al who analysed 58957 patients undergoing angiography ${ }^{(12)}$. The study established that restricting the contrast volume to less than thrice and preferably twice the creatinine clearance was valuable in reducing the risk of CIN.

Despite the multitude of data regarding the optimal ratio of $\mathrm{V} / \mathrm{CrCl}$ in the prediction of $\mathrm{CIN}$, there is a paucity of data analysing the ideal $\mathrm{V} / \mathrm{CrCl}$ ratio in stage III CKD patients undergoing PCI. Our study cohort of CKD stage III patients had a high incidence of the baseline risk factors for $\mathrm{CIN}$ and the mean contrast volume used was $206.4+/-58.3 \mathrm{ml}$. The aggregate of all these risk factors probably contributed to the high incidence of CIN in our study (29\%). In the current study it was unequivocally established the $\mathrm{V} / \mathrm{CrCl}$ ratio > 4 was an independent risk factor for the development of CIN in stage III CKD patients undergoing PCI.

Interstingly there is a wide variation in the $\mathrm{V} / \mathrm{CrCl}$ ratio for prediction of CIN among the available studies. Different studies have quoted different cut off values for predicting CIN ranging from $\mathrm{V} / \mathrm{CrCl}>2.76$ (Yong Liu et. al) to >6.15 (Barbieri et. al) ${ }^{(14)(15)}$. These data are not strictly comparable with those reported in the current study because of the differences in the total number of the patients studied, the number of patients with chronic kidney disease, the definition of CIN and the overall incidence of CIN. It is pertinent to recognize that the predictive value of $\mathrm{V} / \mathrm{CrCl}$ depend upon the baseline incidence of CIN in the population which in turn depends on baseline risk parameters as well as the definition used for the diagnosis of CIN. For instance, in the study by 
Altmann et. al CIN was defined as a rise in serum creatinine of more than $1 \mathrm{mg} / \mathrm{dl}$ within $48 \mathrm{hrs}$, the austere criteria resulted in a low incidence of CIN in the study of only $7 \%^{(18)}$. Importantly this could have lead to the higher cutoff values for $\mathrm{V} / \mathrm{CrCl}$. Similarly the study by Laskey et al analysed patients only for the early \{within 24 hours rise in serum creatinine, in all probabability this could have underestimated the incidence of CIN and altered the $\mathrm{V} / \mathrm{CrCl}$ ratio.

In contrast to the previous studies, we included patients with CKD Stage III and tried to establish a simple index, easily obtainable at the bedside by dividing the volume of contrast media received by the patient's creatinine clearance to predict the occurrence of CIN. Our study demonstrates that in even in patients with baseline renal dysfunction, the $\mathrm{V} / \mathrm{CrCl}$ ratio can independently predict the occurrence of CIN when a threshold of 4 is exceeded.

Although numerous clinical, demographic, and procedural factors are significantly associated with $\mathrm{CIN}$ after PCI, the fact that $\mathrm{V} / \mathrm{CrCl}$ remained independently associated with the risk of an early post procedural creatinine increase after adjustment for these important confounders is supportive of our original hypothesis. Thus, multiplying a patient's estimated creatinine clearance by 4 would give an estimate of the maximum amount of contrast to be used for a given procedure, above which the likelihood of developing renal injury would be monumental.

\section{Limitations}

Our study had a few limitations. Impotranaly our analysis is limited by its post hoc, observational nature. Further CIN has a multifactorial causation in which contrast media is only one of the many factors. Although statistical adjustment was attempted by means of a multivariable model, the impact of unidentified confounders on our findings cannot be entirely ruled out.

\section{Abbreviations}

Contrast induced nephropathy: CIN

Chronic kidney disease: CKD
Coronary artery disease: CAD

Chronic total occlusion: CTO

Estimated glomerular filtration rate: eGFR

Percutaneous coronary intervention: PCI

Mehran risk score: MRS

European Society of Urogenital Radiology: ESUR

Central venous pressure: CVP

Modification of Diet in Renal Disease: MDRD

\section{References}

1. Osborne Ed, Sutherland CG, Scholl AJ et al Roentgenography of urinary tract during excretion of Sodium Iodide. JAMA; 1923 Feb 10; 80:368.

2. Brooks .B Intraarterial injection of Sodium Iodide.JAMA; 1924 Mar 29; 82:1016.

3. Persson PB, Hansell P, Liss P. Pathophysiology of contrast mediuminduced nephropathy. Kidney Int. 2005 Jul; 68:14-22.

4. Almén T. Contrast media: the relation of chemical structure, animal toxicity and adverse clinical effects. Am J Cardiol 1990 Oct 26;66:2F-8F.

5. Rudnick MR, Goldfarb S, Wexler L et al. Nephrotoxicity of ionic and nonionic contrast media in 1196 patients: a randomized trial. The Iohexol Cooperative Study. Kidney Int 1995 Jan;47:254-61.

6. Thomsen HS. European Society of Urogenital Radiology ( ESUR ) guidelines on the safe use of iodinated contrast media. 2006;60:307-13.

7. Chalmers N, Jackson RW. Comparison of iodixanol and iohexol in renal impairment. Br J Radiol 1999 Jul;72:701-3.

8. Jo S-H, Youn T-J, Koo B-K, Park J-S, Kang H-J, Cho Y-S, et al. Renal toxicity evaluation and comparison between visipaque (iodixanol) and hexabrix (ioxaglate) in patients with renal insufficiency undergoing coronary angiography: the RECOVER study: a randomized controlled trial. J Am Coll Cardiol . 2006 Sep 5; 48:924-30. 
9. Eisenberg RL, Bank WO, Hedgock MW. Renal failure after major angiography can be avoided with hydration. AJR Am J Roentgenol . 1981 May ;136:859-61.

10. Trivedi HS, Moore H, Nasr S, et al. A randomized prospective trial to assess the role of saline hydration on the development of contrast nephrotoxicity. Nephron Clin Pract . 2003 Jan; 93:C29-34.

11. Hoffmann U, Fischereder M, Krüger B, Drobnik W, Krämer BK. The value of Nacetylcysteine in the prevention of radiocontrast agent-induced nephropathy seems questionable. J Am Soc Nephrol . 2004 Feb; 15:407-10.

12. Gurm HS, Dixon SR, Smith DE et al. Renal function-based contrast dosing to define safe limits of radiographic contrast media in patients undergoing percutaneous coronary interventions. J Am Coll Cardiol 2011;58:907-14.

13. Laskey WK, Jenkins C, Selzer F et al. Volume-to-Creatinine Clearance Ratio. A Pharmacokinetically Based Risk Factor for Prediction of Early Creatinine Increase After Percutaneous Coronary Intervention. J Am Coll Cardiol. 2007;50:584-90.

14. Tan N, Liu Y, Zhou Y-L et al. Contrast medium volume to creatinine clearance ratio: A predictor of contrast-induced nephropathy in the first 72 hours following percutaneous coronary intervention. Catheter Cardiovasc Interv 2012 Jan 1;79:70-5.

15. Barbieri L, Verdoia M, Marino Pet al Novara Atherosclerosis Study Group. Contrast volume to creatinine clearance ratio for the prediction of contrast-induced nephropathy in patients undergoing coronary angiography or percutaneous intervention. Eur J Prev Cardiol. 2016 Jun 2;23:931-7.
16. Cigarroa RG, Lange RA, Williams RH, et al. Dosing of contrast material to prevent contrast nephropathy in patients with renal disease. Am J Med. 1989 Jun;86:649-52.

17. Freeman R V, O'Donnell M, Share D, Meengs WL, Kline-Rogers E, Clark VL, et al. Nephropathy requiring dialysis after percutaneous coronary intervention and the critical role of an adjusted contrast dose. Am J Cardiol . 2002 Nov 15;90:1068-73.

18. Altmann DB, Zwas D, Spatz A et al Use of the Contrast Volume to Estimated Creatinine Clearance Ratio to Predict Renal Failure After Angiography. J Interv Cardiol 1997 Apr 1; 10:113-9. 